\title{
Anionic salivary proteins associated with connective tissue disorders: sialated tissue kallikreins
}

\author{
D GREAVES ${ }^{1}$ J T WHICHER ${ }^{4}$ K D BHOOLA ${ }^{2}$ C SCULLY, ${ }^{1}$ S FLINT, ${ }^{1}$ \\ $S$ R PORTER, ${ }^{1}$ R E CHAMBERS ${ }^{3}$ P A MADDISON, ${ }^{5}$ A BEELEY, ${ }^{6}$ AND \\ R MATTHEWS
}

From the Departments of ${ }^{1}$ Oral Medicine, ${ }^{2}$ Pharmacology, and ${ }^{3}$ Chemical Pathology, University of Bristol, Bristol, UK; the ${ }^{4}$ Department of Chemical Pathology, University of Leeds, Leeds, UK; ${ }^{5}$ Royal Hospital for Rheumatic Disease, Bath; and the ${ }^{6}$ Oral Biochemistry Unit, University of Glasgow Dental School, Glasgow

SUMmaRY Parotid saliva was collected from 32 patients with rheumatoid arthritis, 10 with systemic lupus erythematosus, three with mixed connective tissue disease, 12 with progressive systemic sclerosis, two with primary Sjögren's syndrome, and four with Raynaud's syndrome. Tissue kallikreins were measured by radioimmunoassay, and saliva samples were subjected to isoelectric focusing followed by immunoblotting or silver staining. The results showed that the saliva of patients with connective tissue diseases contained increased amounts of immunoreactive tissue kallikrein. In addition, there was an increase in the multiple forms of anionic tissue kallikreins, resulting mainly from a shift in their distribution towards that of higher sialic acid content and lower isoelectric point. These changes were most obvious in patients with systemic lupus erythematosus. Novel or unusual glycosylation may explain the occurrence of increased amounts of anionic salivary proteins in connective tissue diseases.

A frequent complication of connective tissue diseases is secretory failure of exocrine glands, including the lacrimal and salivary glands, leading to dry eyes and dry mouth. This is known as secondary Sjögren's syndrome ${ }^{1}$ and is often associated with rheumatoid arthritis, systemic lupus erythematosus, progressive systemic sclerosis, and mixed connective tissue disease. ${ }^{2}$ Primary Sjögren's syndrome has no associated connective tissue disorder and differs from the secondary form clinically, serologically, and genetically.

A number of studies, using electrophoretic techniques of varying resolution, have shown that the saliva from patients with Sjögren's syndrome contains increased amounts of several anionic proteins. ${ }^{3-6}$ Furthermore, these proteins appear more frequently in the secondary form of the disease, and have been described in the saliva of patients with rheumatoid arthritis but without clinical evidence of salivary gland involvement. ${ }^{7}$ Although these anionic salivary proteins have been

Accepted for publication 8 February 1989.

Correspondence to Dr K D Bhoola. Department of Pharmacology, Medical School, University of Bristol, University Walk. Bristol BS8 1TD, UK. subjected to concerted investigations, their identity has remained obscure. The initial aim of this study was to identify and characterise these proteins, and to ascertain whether they were more prevalent in a group with a particular connective tissue disease. By chance, we discovered that the dominant group of these anionic proteins in connective tissue diseases were tissue kallikreins (E.C.3.4.21.35), which are normally present in saliva, and whose anionic nature is conferred by their sialic acid composition.

Tissue kallikreins are present in a wide variety of tissues. ${ }^{8}$ They are members of a multigene family of serine proteases known to cleave kininogen and precursors of hormones to produce biologically active peptides. Clearly, the exciting possibility of unusual or novel glycosylation of proteins like tissue kallikrein may be important in our understanding of the primary cellular defect in connective tissue diseases.

\section{Patients and methods}

PATIENTS

We studied 63 patients (female 45 , male 18 ; mean age 53.5 years, range $18-82$ years) with connective tissue diseases ( 32 rheumatoid arthritis, 10 systemic 
lupus erythematosus, 3 mixed connective tissue disease, 12 progressive systemic sclerosis, 2 primary Sjögren's syndrome, 4 primary Raynaud's syndrome), who were diagnosed as definite or classical connective tissue disease according to American Rheumatism Association criteria, ${ }^{10}$ and 45 healthy patients matched for age and sex as controls. Ten patients were taking no drugs while the remainder were taking two or more drugs. We classified these into non-steroidal anti-inflammatory (38 patients), steroids, immunomodulatory, and other (comprising diuretics, antihypertensives, antidepressants, etc) drug groups.

\section{SAMPLE COLLECTION}

Parotid saliva, stimulated with citric acid $(1 \%)$, was collected by mild suction of saliva from the parotid duct orifice through silicone tubing into a plastic tube kept on ice. The collections were performed mid-morning as salivary secretory proteins show diurnal variation. Samples were frozen and stored at $-20^{\circ} \mathrm{C}$ until assayed. Urine was collected at the same time as saliva from the patients with connective tissue diseases and from the healthy controls.

\section{ISOELECTRIC FOCUSING}

Samples were freeze dried and reconstituted to a protein content ${ }^{11}$ of $6 \mu \mathrm{g} / \mu \mathrm{l}$ for isoelectric focusing, which was performed on polyacrylamide gels $(4 \cdot 8 \%)$ over a pH gradient of 2.5 to 6.0 using $25 \mu$ l samples.

The gels were stained sequentially with Coomassie brilliant blue $\mathrm{G}^{250^{7}}$ (45 minutes) then silver stain ${ }^{12}$ after several washes (30 minutes) in deionised water. Gels were dried and wrapped in cellophane preserving sheets supported on Gelbond (Miles Scientific, Slough, UK) before scanning on a laser densitometer (Ultroscan, LKB Produkter, Bromma, Sweden). The intensity of bands shown on the silver stained electrophoretograms of pI 3.0-4.0 (determined using a surface electrode) was expressed as integrated density (the total absorbance of the band). The intergel variation in measured density of a single band was $9 \cdot 4 \%(n=20)$.

HUMAN TISSUE KALLIKREIN: STANDARDS AND ANTISERA

Purified human tissue kallikrein ${ }^{13}$ of urinary origin (kindly provided by Professor M Moriya, Japan) was used as a standard in the radioimmunoassay ${ }^{14}$ and on the electrophoretograms both for silver staining and immunoblotting. Human urinary kallikrein was purified ${ }^{14}$ by silica gel absorption, gel filtration on Sephadex G-75, DEAE-Sephadex, and affinity chromatography, with the final step involving rapid gel filtration. The pure preparation was heterogeneous consisting of three isoenzymes of pI $3 \cdot 9,4 \cdot 0$, and $4 \cdot 2$. Enzymic activity was equivalent. to $4.6 \mathrm{units} / \mathrm{mg}$ protein (one unit hydrolyses $1 . \hat{\theta}$. $\mu \mathrm{mol}$ of $\mathrm{D}-\mathrm{Val}-\mathrm{Leu}-\mathrm{Arg}$-pNA nitroanilide/min pH 8.0 and $37^{\circ} \mathrm{C}$ ). Human salivary kallikrein was purified by a modification of the method describe by Lemon et al. ${ }^{15}$ After absorption of the enzyme to DEAE-cellulose and gel filtration through Sephæ dex G-100 it was chromatographed twice off DEAE-Sephadex A-50. The final step involved. passage through CNBr-Sepharose 4B coupled to antihuman albumin. The specific enzymic activity of this preparation was 38 units/mg protein.

Polyclonal antibodies specific to human urinary and salivary kallikrein were raised in rabbits. Specificity of the antisera was determined by Oucho terlony gel diffusion, immunoblotting, and radioimmunoassay. ${ }^{14}$ In gel diffusion human urinary and salivary kallikrein showed complete immunological identity when reacted against both antisera. In addition, both human urinary and salivary kallikreiop cross reacted in an identical manner with antisera raised to human urinary kallikrein by $\mathrm{Dr} C \mathrm{Vi}$ Faculty of Biological Sciences, Catholic Universit Santiago, Chile and by Dr David Proud, Division of Clinical Immunology, John Hopkins Unive fi School of Medicine, Baltimore, USA. No reaction was observed with aprotinin, urokinase, tas minogen, thrombin, human albumin, or trypsin?

\section{IM M U N O B L O T T ING}

Electroblotting was performed on $0.45 \mu \mathrm{m}$ nitrके cellulose (Transphor 2005, LKB-Produkter) transfer buffer pH 8.3 (25 mM TRIS- $\mathrm{HCl}, 150 \mathrm{~m}$ glycine, $20 \%$ methanol). Rabbit antisera $(10 \mathrm{~min}$, $1 / 200$ dilution) to IgA, IgM, IgG, secreto component, $x$ light chains, $\lambda$ light chains, lysozyme, $\beta_{2}$-microglobulin, $\alpha_{1}$-acid glycoprotein, $C$ reactime protein, serum amyloid $\mathrm{P}$ component, $\mathrm{C} 1$ esterase inhibitor (Dakopatts, Copenhagen, Denmark玉, tissue kallikrein, and salivary acidic proline-rich proteins (kind gift of Professor A Bennick, Torontg) were used as the first stage of the unlabelled bridge technique. Swine antirabbit antiserum $(10 \mathrm{ml}, 1 / 400$ dilution) formed the link with the rabbit antip oxidase/peroxidase complex $(10 \mathrm{ml}, 1 / 400$ dilution $)$ (Dakopatts). The blot was stained with 3-amino- 85 ethylcarbazole (stock solution: $1 \%$-amino 20 ethylcarbazole in acetone, $25 \mathrm{ml} 0.05 \mathrm{M}$ sodiug acetate buffer pH 5.0, $15 \mu \mathrm{l} 30 \% \mathrm{H}_{2} \mathrm{O}_{2}$ ). Immunfblots were also prepared on saliva samples incubated with neuraminidase (Sigma, Poole, Dorse UK) at a concentration of $1 \mathrm{mg} / \mathrm{ml}$ of saliva for $\$ 6$ hours at $4^{\circ} \mathrm{C}$. Kallikrein concentrations were measured before and after neuraminidase treatme to determine whether the radioimmunoassay wa্의 
affected by the sialic acid content of the acidic forms of the enzyme

STATISTICAL ANALYSIS OF THE DATA Cumulative frequency curves of the integrated density of bands in the pI 3.0-4.0 range for groups with connective tissue disease and control groups were fitted to the logistic expression ${ }^{16}$ :

$$
Y=\frac{X^{P}}{X^{P}+K^{P}}
$$

where $\mathrm{Y}$ is the density, $\mathrm{K}$ the $50 \%$ value, and $\mathrm{P}$ the slope. The same expression was used to determine the distribution of tissue kallikrein values $(\mathrm{Y}=$ tissue kallikrein in $\mathrm{ng} / \mu \mathrm{g}$ parotid salivary protein) in each group. In addition, the data were analysed by the non-parametric Mann-Whitney $U$ test and band density compared with tissue kallikrein concentrations by linear regression analysis.

\section{Results}

Isoelectric focusing of parotid saliva over the $\mathrm{pH}$ range $2 \cdot 5-6 \cdot 0$ showed a very large number of bands when stained with a sensitive silver stain (Fig. 1a). The proline-rich proteins, ${ }^{17}$ which show inconsistent staining characteristics on silver staining, dominate the pattern between $\mathrm{pH} 4 \cdot 0$ and $\mathbf{4 \cdot 8}$. For this reason we chose to study the most anodal proteins in the $\mathrm{pH}$ range $3 \cdot 0-4 \cdot 0$, which appeared on preliminary assessment to be present in increased amounts in some patients with connective tissue diseases.

Immunoblotting of the anionic bands with antisera to a wide range of human serum and salivary proteins (see 'Patients and methods') showed reactivity primarily against human tissue kallikrein. A complex pattern of 12 immunoreactive tissue kallikrein bands was seen. Six of those present in the 'anionic region' (pI 3.0-4.0) represented the bands whose intensity was measured after silver staining (Fig. 1b). A further six bands were present in the $\mathrm{pI}$ range 4.0-5.0 and three in the pI range 4.0-4.25. The intensity of these bands, which had not been clearly visualised on silver staining owing to the presence of several overlapping non-kallikrein bands, did not vary in parallel with those in the anionic region. Two faint bands reacting with anti$\alpha_{1}$-acid glycoprotein were seen at pI $2 \cdot 7$. Treatment of saliva samples and purified tissue kallikrein with neuraminidase largely removed the anodal kallikrein bands and resulted in their shift to a higher pI value (Figs 1a and $b$ ).

Analysis of the silver stained bands (Fig. 1a), measured by laser densitometry, showed a clear increase in anionic proteins in the saliva of some

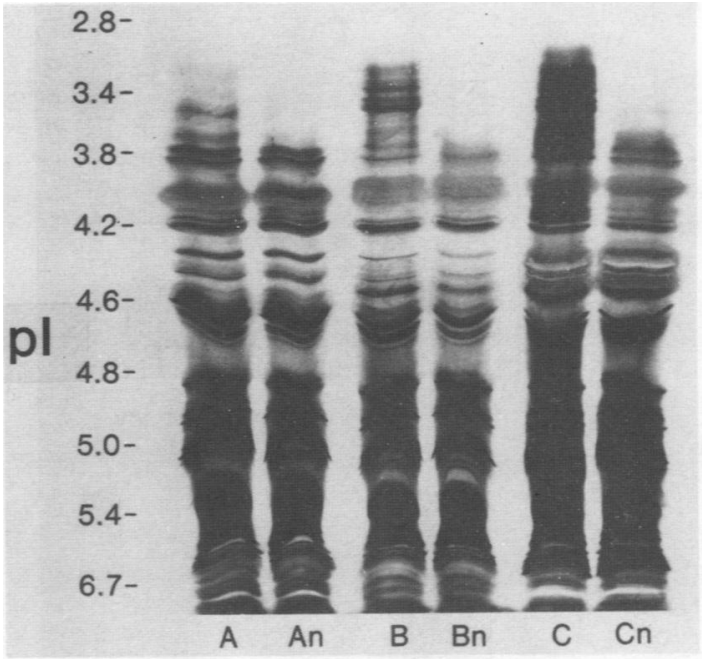

Fig. 1a

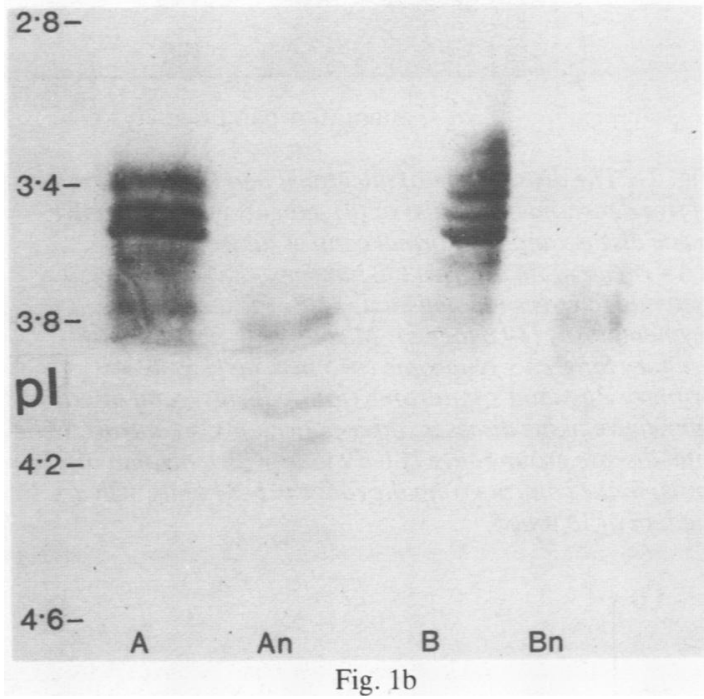

Fig. 1 (a) Silver stained, isoelectrically

focused saliva samples before and after (n) treatment with neuraminidase. $A=$ normal saliva with a low concentration of anionic bands (representing the region 2.0 to 4.0 integrated density units); $B=$ normal saliva with a higher concentration of anionic bands (representing the region 7.0 to 8.0 integrated density units); $C=$ saliva from a patient with rheumatoid arthritis and a high concentration of anionic bands (representing the region 14.0 to 16.0 integrated density units). For integrated density units refer to Fig. 2. (b) Salivary samples from a normal subject containing a high concentration of anionic bands $(A)$ and a patient with systemic lupus erythematosus $(B)$ immunoblotted with anti-tissue kallikrein before and after (n) treatment with neuraminidase. 


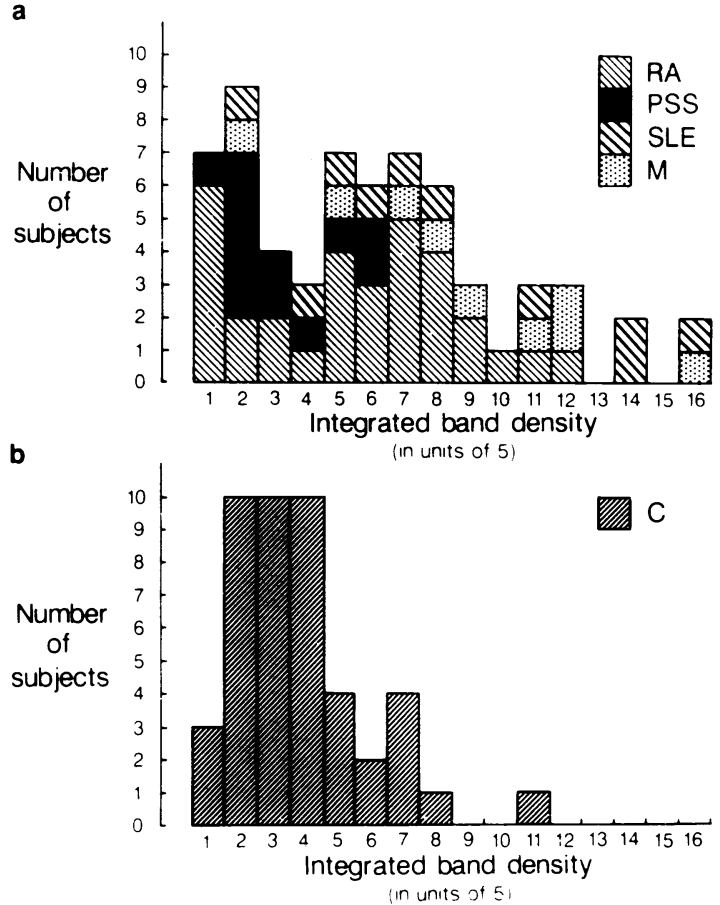

Fig. 2 The distribution of integrated band density (groups of five densitometric units) in (a) patients with connective tissue disease and (b) normal control subjects.

$R A=$ rheumatoid arthritis ( 32 patients); $P S S=$ progressive systemic sclerosis (12 patients); $S L E=$ systemic lupus erythematosus (10 patients); $M$ comprises patients with primary Sjögren's syndrome (two patients),

primary Raynaud's syndrome (four patients), and mixed connective tissue diseases (three patients); $C=$ controls. (The total disease group range is 1-79 units with a median of 27 units; in the control group the range is 1-54 units with a median of 15 units). patients with connective tissue diseases whe compared with normal controls (Fig. 2). Thesक. findings were examined statistically by $\operatorname{Dr} \mathrm{R}$ B. Barlow. ${ }^{16}$ The reason for fitting the data to a logistie? expression was to determine whether the contro $\Phi$ and connective tissue disease values represente single or multiple populations. As evident from Fig $\frac{\bar{\rho}}{\sigma}$ 3 the cumulative frequency curve indicated th\& presence of at least two populations in the cones nective tissue disease values, in contrast with the single population in the control data. Such impor: tant information cannot be readily ascertained from single means and standard error of the mean. I seems that systemic lupus erythematosus shows thष्ष greatest prevalence of high intensity silver staining in the anodal region and progressive systemie sclerosis the least (see Fig. 2). The possible in fluence of treatment on this relation was exclude by comparing band intensity in those patients taking no drugs with those prescribed drugs, using a twQ sided Mann-Whitney test; no significant differencess $(p<0 \cdot 2)$ were observed between the two groups. W $\mathbb{D}$ further compared each drug group with those taking no drugs and also found no significant differences

Immunoreactive salivary tissue kallikrein concen $\frac{\mathbb{N}}{\mathscr{N}}$ trations, measured by radioimmunoassay, w8re $\overrightarrow{0}$ significantly higher in the group with connective tissue diseases than in the controls (Fig. 4). Un迹定 the silver staining, none of the individual dise as groups was significantly different from the others Furthermore, there was no correlation between the tissue kallikrein concentrations and the intensity of the anodal bands either in the controls $(r=0.561)$ of the group with connective tissue disease $(r=0 \cdot 371) \overrightarrow{\overrightarrow{0}}$ Neuraminidase treatment did not alter the salivar tissue kallikrein concentrations measured by radio immunoassay.

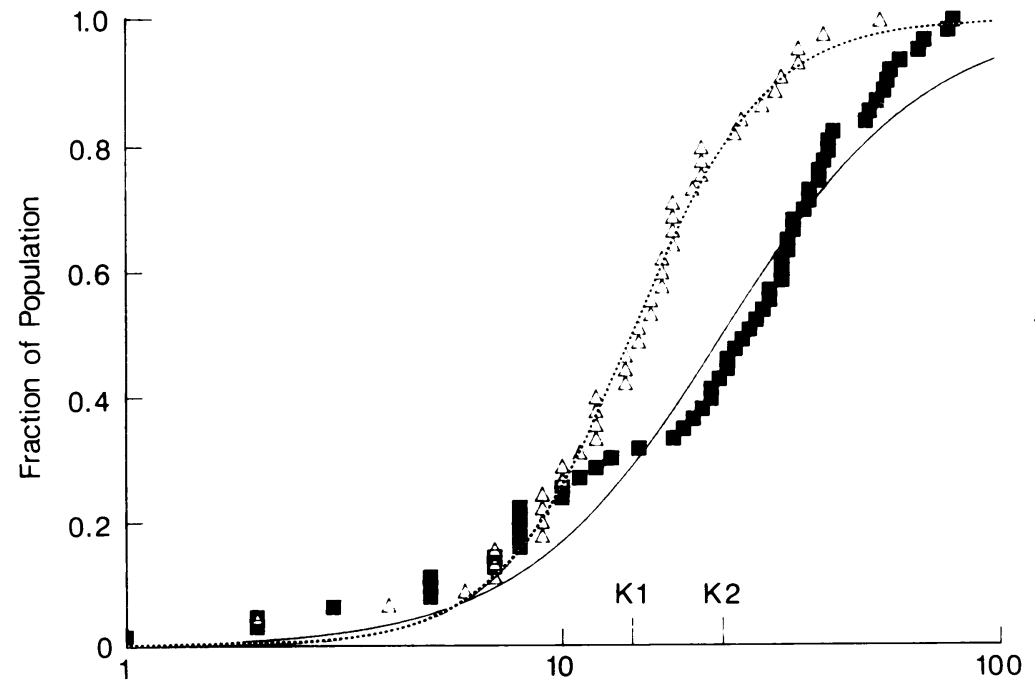

Fig. 3 Cumulative frequency curves obtained by integrating the density values for controls $(\triangle \ldots \ldots \Delta)$ and patients with connective tissue diseases (ㄴ). The logistic expression $\frac{7}{8}$ values for the controls $(n=45)$ are $K I=14 \cdot 45 / 0 \cdot 12, P I=2 \cdot 88 / 0 \cdot 08$ and N for connective tissue

diseases $(n=63) \mathrm{K} 2=23 \cdot 40 / 0 \cdot 18$, $P 2=1 \cdot 88 / 0 \cdot 08$. The connective tissue disease curve is shifted to the right, indicating that anionic bands of higher integrated density occur more commonly in this group, and $\mathbb{\mathscr { D }}$ the distribution indicates the presence of more than one population in this group. This finding is more clearly seen on the histogram in Fig. 2. 


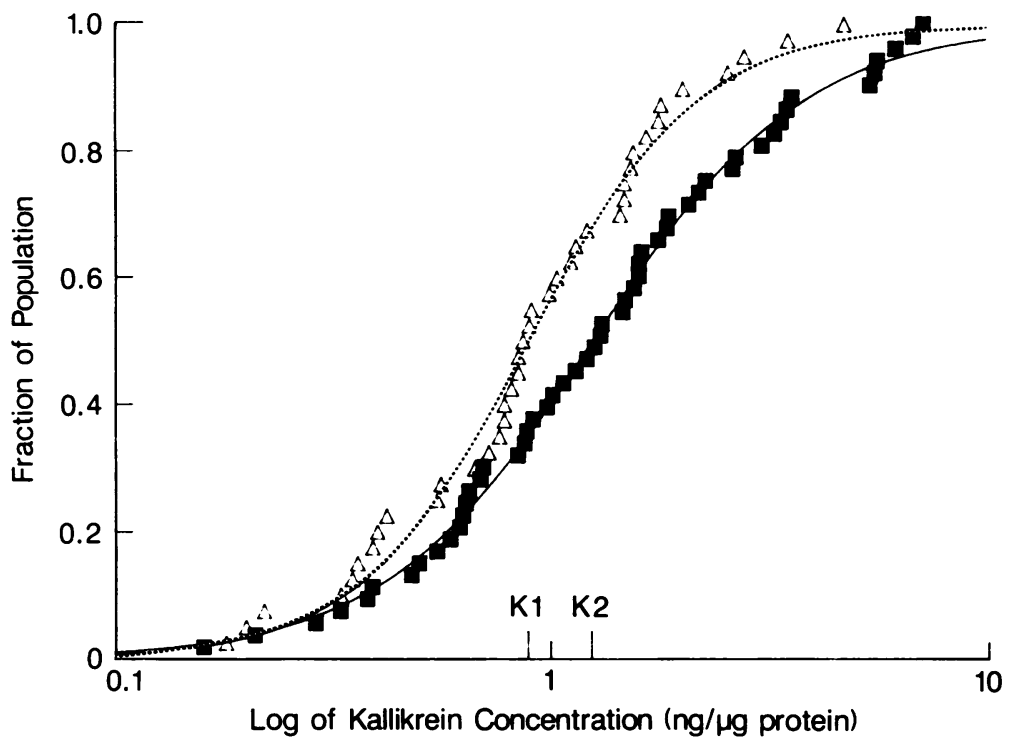

Fig. 4 Cumulative frequency curves for tissue kallikrein values in the controls $(\triangle \ldots \ldots \triangle)$ and patients with connective tissue diseases ( $\square)$. The logistic expression values for the controls $(n=40)$ are $K 1=0 \cdot 89 / 0 \cdot 01 ; P=2 \cdot 26 / 0 \cdot 08$ and for connective tissue diseases $(n=53) \mathrm{K} 2=1 \cdot 2410 \cdot 01 ; P=1 \cdot 81 / 0 \cdot 08$. Although the frequency distribution curve shows similar populations for both groups, the curve for connective tissue disease is significantly shifted to the right, indicating the occurrence of greater tissue kallikrein values and variance in the patients with connective tissue diseases. When the data were analysed by linear regression no significant correlation was evident between the tissue kallikrein values and the density of the anionic bands either in the normal group $(r=0.560)$ or the group with connective tissue diseases $(r=0.377)$. The tissue kallikrein values were: control group, mean $1 \cdot 16 \mathrm{ng} / \mathrm{g}$ protein, range $0 \cdot 18-4 \cdot 68$; connective tissue disease group, mean $1 \cdot 89$, range $0 \cdot 16-7 \cdot 08$.

Samples of urine from a subgroup of eight patients and 11 controls were examined by isoelectric focusing and immunoblotting. Preliminary experiments indicated that there was no variation in intensity of anionic bands (pI 3.0-4.0), paralleling the results seen in saliva. The bands present in the $\mathrm{pI}$ 4.0-5.0 range were more intense in the urine samples than those observed in saliva.

\section{Discussion}

Using isoelectric focusing, sensitive silver staining, and laser densitometry, we have been able to show that there is a wide distribution in concentration of proteins forming multiple bands with a pI of between 3.0 and 4.0 in the saliva of both normal subjects and patients with connective tissue diseases. We have identified most of these protein bands as multiple forms of tissue kallikrein (E.C.3.4.21.35), which on treatment with neuraminidase acquired a more cathodal electrophoretic mobility owing to removal of sialic acid residues. Furthermore, most bands identified as tissue kallikrein have a lower pI
(3.0-4.0) than the bands previously described by Mairs and Beeley ${ }^{7}$ (pI 3.95-4.25). There is, however, some overlap and a particularly prominent band seen in their electrophoretograms at pI 3.95 is clearly evident on our separations as tissue kallikrein. The greater sensitivity of the silver staining technique has allowed us to visualise the more anodal proteins, which are not seen with the Coomassie blue staining technique. Immunoblotting suggests that most bands in the pI range 3.95-4.25 are tissue kallikreins, but that there are also proteins rich in proline,${ }^{17}$ and rheumatoid factors as shown by Mairs and Beeley. ${ }^{7}$ The proline-rich proteins show variable staining using silver and for this reason we chose not to measure the bands with a pI greater than 4.0.

We have shown that the concentration of immunoreactive tissue kallikrein in the parotid saliva of patients with connective tissue diseases was significantly greater than in normal controls. In contrast, normal values have been published for enzymically active tissue kallikrein in parotid or submandibular saliva in patients with rheumatoid 
arthritis. ${ }^{18}$ Several studies have stated that enzymically active tissue kallikrein in whole rheumatoid arthritis saliva was either normal or raised. ${ }^{19}{ }^{20}$ Such differences in concentrations are probably due to the lack of specificity in the synthetic substrates used to measure the active enzyme.

From our results it is evident that patients with rheumatoid arthritis, systemic lupus erythematosus, mixed connective tissue disease, and Raynaud's syndrome have a greater quantity of anionic tissue kallikrein in their saliva. Furthermore, this finding did not appear to be related to the degree of clinically overt Sjögren's syndrome. It is notable that patients with progressive systemic sclerosis have normal concentrations of anionic proteins. Of relevance is the observation that tissue kallikrein concentrations were decreased in patients with sarcoidosis, even though there was no clinical evidence of salivary gland involvement. ${ }^{21}$ Our failure to find a clear correlation between the increased anionic forms and altered exocrine gland function may reflect the presence of a glycosylating defect before the appearance of clinically noticeable symptoms. Subsequent progression of the disease may involve additional factors.

In view of the widespread cellular sites of localisation of the kallikrein group of serine proteases we examined the urine of a small group of patients and normal subjects. Urinary kallikrein is thought to originate mainly from the renal connecting tubule cells. ${ }^{22}$ Anionic kallikrein bands sensitive to neuraminidase were present in the urine at low concentrations in both normal subjects and patients. The absence of high intensity anionic bands in urine paralleling those in saliva suggests, however, that the multiple anionic forms of tissue kallikrein synthesised in the salivary duct cell are not expressed in the renal connecting tubule cells. In urine, kallikrein bands of $\mathrm{pI} 4 \cdot 0-5 \cdot 0$ showed a greater intensity of staining than those in saliva. Differences in both structure and regulation of synthesis of salivary and urinary tissue kallikreins have been suggested on the basis of both immunochemical and pharmacological studies. ${ }^{23}$

One explanation for the multiple anionic forms in parotid saliva may be the sequential removal of carbohydrate chains from the tissue kallikrein molecule by neuraminidase arising from desquamated inflammatory cells. The major component of human salivary kallikreins has a pI value of 3.9. Thus the unlikely hydrolysis of sialic acid residues by neuraminidase from inflammatory cells may only mask anionic forms of the enzyme with even lower pI values.

Normal carbohydrate microheterogeneity, due to the linking of different sialic acid residues to the parent protein, has been well described in pig submandibular ${ }^{15}$ and pancreatic kallikrein, ${ }^{24}$ and in rat $^{25}$ and human ${ }^{1326-28}$ urinary kallikrein. The presence therefore of increased amounts of anionico molecules of tissue kallikrein in the saliva of patients with connective tissue diseases suggests either that there is a primary genetic abnormality linking thesês. diseases and certain anionic forms of kallikrein o $\vec{D}$ that early disease within the gland causes a posto transcriptional change which modifies the carbo $=$ hydrate side chain substitution of the kallikrein $\vec{P}$ molecules. Whether such an alteration in the syn $=$ thesis of unusual or novel acidic carbohydrate moieties could account for the secretion of low $\mathrm{p}$ anionic kallikrein by salivary duct cells, and whethe? such a change has any relevance to the pathogenesiṣo of connective tissue diseases, are open questions.

We acknowledge financial support from the Medical Researcto Council.

\section{References}

1 Moutsopoulous H M, Chused T M, Mann D L, et al. Sjögren' syndrome (sicca syndrome): current issues. Ann Intern Med 1980; 92: 212-26.

2 Strand V, Talal N. Advances in the diagnosis and concep尺o ofio Sjögren's syndrome (autoimmune exocrinopathy). Bull Rheinco Dis 1980; 30: 1046-52.

3 Fischer C J, Wyshak G H, Weisberger D. Sjögren's syndrome electrophoretic and immunological observations on serum an $\$$ salivary proteins of man. Arch Oral Biol 1968; 30: 257-70.

4 Chisholm D M, Beeley J A, Mason D K. Salivary proteins ip Sjögren's syndrome: separation by isoelectric focusing i⿱⺈ acrylamide gels. Oral Surg Oral Med Oral Pathol 1973; 358 620-30.

5 Herzberg M, White C, Wolf R O. Characterization of salivar要 proteins in patients with Sjögren's syndrome. Oral Surg Orat Med Oral Pathol 1973; 36: 814-7.

6 Benedek-Spat E, Puskas M, Rajki J. Electrophoretic protein pattern of human parotid saliva in Sjögren's syndrome and sialosis. Acta Otolaryngol (Stockh) 1980; 90: 275-82.

7 Mairs R J, Beeley J A. Partial characterization of abnorma? salivary proteins associated with rheumatoid arthritis. Clin $\mathrm{SCT}$ 1985; 69: 727-35.

8 Shine J, Mason A J, Evans B A, Richard R I. The kallikrei multigene family: specific processing of biologically active peptides. Cold Spring Harbor Symp Quant Biol 1983; 48. 419-26.

9 Evans B A, Yun Z X, Close J A, et al. Structure an $\$$ chromosomal localization of the human renal kallikrein gene로․ Biochemistry 1988; 27: 3124-9.

10 Masi A T, Rodnan G P, Medsger T A, et al. Preliminary criteriô for the classification of systemic sclerosis (scleroderma). Bull Rheum Dis 1981; 31: 1-6.

11 Bradford M M. A rapid and sensitive method for the quantis tation of microgram quantities of protein utilizing the principle of protein-dye binding. Anal Biochem 1976; 72: 248-54.

12 Morrisey J H. Silver stain for polyacrylamide gels: a modifieळ procedure with enhanced uniform sensitivity. Anal Biocher 1981; 117: 307-10.

13 Matsuda Y, Miyazaki K, Moriya H, Fujimoto Y. Human renál kallikrein: purification and some properties. Chem Pharm Bulf (Tokyo) 1981; 29: 2106-8. 
14 Bagshaw A F, Bhoola K D, Lemon M J C, Whicher J T. Development and characterization of a radioimmunoassay to measure human tissue kallikrein in biological fluids. Endocrinology 1984; 11: 173-9.

15 Lemon M, Fiedler F, Forg-Brey B, Hirschauer C, Leysath G, Fritz $H$. The isolation and properties of pig submandibular kallikrein. Biochem J 1979; 177: 159-68.

16 Barlow R B. In: Biodata handling with microcomputers. Cambridge: Elsevier, Biosoft, 1983: 55-61.

17 Oppenheim F G, Hay D I, Franzblau C. Proline-rich proteins from human parotid saliva. I. Isolation and partial characterization. Biochemistry 1971; 10: 4233-8.

18 Matthews R W, Bhoola K D, Rasker J J, Jayson M I V. Salivary secretion and connective tissue disease in man. Ann Rheum Dis 1985; 44: $20-6$.

19 Kerby G P, Taylor S M. Salivary kallikrein levels in normal and in rheumatoid individuals. J Lab Clin Med 1968; 71: 704-8.

20 Grimaldi M G, Preda A, Scanni A, Dell Aquila F. Scialografia tasso di callikreina salivare e scialobiopsia in corso di malattia reumatoide. Reumatismo 1971; 23: 252-6.

21 Bhoola K D, McNicol M W, Oliver S, Foran J. Changes in salivary enzymes in patients with sarcoidosis. $N$ Engl $J$ Med 1969; 281: 877-9.

22 Vio C P, Figueroa C D. Subcellular localisation of renal kallikrein by ultrastructural immunocytochemistry. Kidney Int 1985; 28: 36-42.

23 Van Leeuwen B H, Grinblat M, Johnston C I. Tissue-specific control of glandular kallikreins. Am J Physiol 1984; 247: F760-4.

24 Ikekita M, Moriya H, Ozawa S, Kizuki K. Studies on heterogeneous components of hog pancreatic kallikrein'possible role of the neuraminic acid residues'. Chem Pharm Bull (Tokyo) 1981; 29: 545-53.

25 Tunes H, Silva E, Mares-Guia M. Alpha and beta rat urinary kallikreins: chemical and physicochemical properties. In: Fritz H, Back N, Dietze G, Haberland G L, eds. Advances in experimental medicine and biology. Kinins III. Vol 156A. New York: Plenum, 1983: 317-27.

26 Moriya H, Ikekita M, Kizuki K. Some aspects of carbohydrate contents in glandular kallikrein. In: Fritz H, Back N, Dietze G, Haberland $G \mathrm{~L}$, eds. Advances in experimental medicine and biology. Kinins III. Vol 156A. New York: Plenum, 1983: 309-16.

27 Hial V, Diniz C R, Mares-Guia M. Purification and properties of a human urinary kallikrein (kininogenase). Biochemistry 1974; 13: 4311-8.

28 Geiger R, Stuckstedte U, Fritz H. Isolation and characterization of human urinary kallikrein. Hoppe-Seyler's Zeitschrift für Physiologische Chemie 1980; 361: 1003-16. 